\title{
Yoga and Meditation as an Adjunct Interventional Strategy for COVID-19 Management
}

\author{
Kishore K. Deepak ${ }^{1}$ Mohan Raghavendra Rao ${ }^{2}$ \\ ${ }^{1}$ Department of Physiology, All India Institute of Medical Sciences, \\ New Delhi, India \\ ${ }^{2}$ Central Council for Research in Yoga and Naturopathy, Ministry of \\ AYUSH, Janakpuri, New Delhi, India
}

Ann Natl Acad Med Sci (India) 2021;57:65-67.

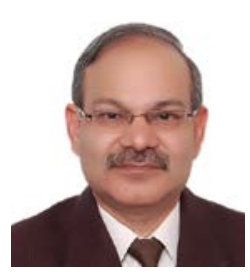

Kishore K. Deepak

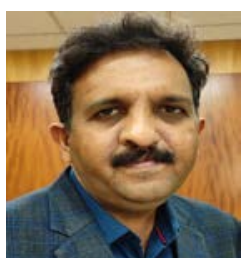

Mohan Raghavendra Rao
There is ample evidence and expanding coverage on the COVID-19 virus spread across the world today. The increasing burden of cases has not only overwhelmed our fragile public health care system but also stressed our economy due to lockdowns. The last one year of the pandemic has subjected our health care systems, social support systems, and resilience of our citizens to testing times, as a result of antipandemic measures. Evidence-based treatment guidelines have been formulated, revised, and advocated by both Ministry of Health and Family Welfare and Ministry of AYUSH in the last one year for health care practitioners to treat COVID-19 patients. There has been a clamor for improving one's "immunity" and being healthy and fit to reduce the impact of COVID-19. While the COVID-19 may infect anybody, the predilection, severity of symptoms, and ability to resist virus infection does depend on physiological and psychological status of one's health. This is evident from epidemiological characteristics of this disease severely affecting the elderly and those with comorbid conditions. Although the evidence for role of a healthy lifestyle as a primary prevention of COVID is still uncertain, it nevertheless is known to influence the trajectory of the disease in those affected. Yoga and meditation as a mind, body and lifestyle intervention has gained popularity in recent times. Ever since the declaration of International Day of Yoga (June 21) by the United Nations General Assembly in 2014, yoga, as a health promotion intervention, has gained popularity globally with due support from majority of the nations and the World Health Organization (WHO). The present editorial highlights the role of yoga in prevention and management of COVID and COVID-like acute respiratory illnesses.

The resurgence of COVID-19 in 2021 has enhanced the burden on the health care resources in our country, with an exponential increase in the number of cases. The highlighting of deaths due to lack of oxygen beds by the media has created a panic in the country. People are more anxious than

\section{Address for correspondence}

Kishore K. Deepak, MD, PhD, FAMS,

DSc, Department of Physiology, All India Institute of Medical Sciences, Ansari Nagar, New Delhi 110029,

India

(e-mail: kkdeepak@gmail.com).
DOI https://doi.org/ 10.1055/s-0041-1731611 ISSN 0379-038X ever before if they have contracted COVID due to uncertainty in trajectory and ensuing respiratory distress. It has become impossible under these circumstances to pay attention to and mitigate the psychological distress of every patient who is under home isolation or under hospitalization. The accompanying psychological distress in COVID-19 patients is often ignored and not managed. There have been reports of anxiety and acute depression, leading to suicides during home isolation and in COVID care hospitals. Social isolation has led to anxiety and led to severe mental health issues in those with preexisting anxiety or depressive disorders. The constant fear of getting infection, unbearable stress, long working hours, helplessness, and distress watching infected patients die alone has caused burnout stress in frontline health care workers. All these point to a pandemic of psychological distress accompanying COVID-19. ${ }^{1}$

COVID-19 patients have had to contend with stress due to fear of worsening of symptoms, respiratory distress, hypoxia, fatigue, insomnia, and other symptoms during COVID-19 infection, which are amplified due to isolation anxiety. ${ }^{2}$ The anxiety and uncertainty about the trajectory and course of illness among COVID-19 positive patients, those suspected of COVID-19, and those in quarantine can lead to psychologic distress which, in turn, can downregulate their immune defenses and increase the chance and severity of infection, similar to earlier studies. Studies have shown psychological stress to enhance the rates of infection in communities during a flu season. Even among the health care workers, impending anxiety and stress can downregulate immune responses and defenses that can lead them to contract this infection and increase its severity. ${ }^{3}$

Treatment protocols for people with COVID-19 should address both the physiological and psychological needs of the patients and health service providers. Providing psychological treatment and support may reduce the burden of

(c) 2021. National Academy of Medical Sciences (India).

This is an open access article published by Thieme under the terms of the Creative Commons Attribution-NonDerivative-NonCommercial-License, permitting copying and reproduction so long as the original work is given appropriate credit. Contents may not be used for commercial purposes, or adapted, remixed, transformed or built upon. (https://creativecommons.org/licenses/by-nc-nd/4.0/).

Thieme Medical and Scientific Publishers Pvt. Ltd. A-12, 2nd Floor, Sector 2, Noida-201301 UP, India 
comorbid mental health conditions and ensure the well-being of those affected. ${ }^{4}$ There is some evidence that enhancing general physical and mental health may reduce burden of acute respiratory illness. In a series of observational and viral inoculation studies, perceived stress, negative emotion, and lack of social support predicted not only self-reported illness but also biomarkers such as viral shedding and inflammatory cytokine activity. ${ }^{5,6}$ Similarly, both epidemiological and experimental studies have suggested that regular physical activity such as moderate exercise may protect people from acute respiratory illness. ${ }^{7}$ A recent observational cohort study ( $n=1,002$ adults) reported $32 \%$ to $46 \%$ lower incidence, duration, and severity of acute respiratory infection (ARI) illness among the most active versus least active participants. ${ }^{8}$

The recommended means of aerobic exercise is walking, with an optimal frequency of three to five days a week and an optimal duration of 20 to 30 minutes of continuous activity. ${ }^{9}$ Moderate exercise is known to increase salivary IgA secretion, which is known to reduce the risk of infections. ${ }^{10}$ In a recent observational study, COVID-19 patients who were physically active and met physical activity guidelines had less severe form of COVID illness. ${ }^{11}$ Studies on yoga and meditation in managing flu symptoms during an influenza season have shown promising results. A recent randomized trial comparing meditation and exercise with wait-list control among adults aged 50 years and older found significant reductions in ARI illness during cold season with mindfulness meditation..$^{12}$ Considering that they are a vulnerable group to contract such infections, yoga may be useful as a preventive measure. In our earlier study, yoga practices such as kriyas, pranayama, and asanas have been shown to reduce airway reactivity and enhance respiratory effort in elderly subjects with asthma. ${ }^{13}$ Thus, modulation of autonomic tone may also be useful in the management of COVID-19 illness, as it can modulate immune response and inflammation. Sufficient evidence exists to justify testing the hypothesis that training in meditation or exercise can reduce susceptibility to ARI illness. The ability of yoga to reduce inflammatory markers in those with obesity or cardiovascular illness and diabetes may be useful in COVID-19 patients with these comorbid conditions. Below is a list of yoga practices that can be used in management of Covid-19 patients (see - Table 1).

Yoga and meditative practices can play an important role as an adjunct in reducing psychosocial distress in the community. Central Council for Research in Yoga and Naturopathy (CCRYN), an autonomous body under the Ministry of AYUSH, has developed a psychosocial rehabilitation program for COVID-19 patients in consultation with National Institute of Mental Health and Neuro Sciences (NIMHANS), Bengaluru, and SVYASA University, wherein AYUSH doctors will be trained in screening for psychosocial distress, counselling, and management of psychosocial distress in COVID-19 patients using yoga and naturopathy approaches. It is important that through socio-culture structuring, the masses are motivated to engage in regular physical activity, yoga, and meditative practices. WHO has taken these initiatives the world over as global action plan on physical activity (GAPPA) program. The fit India movement program of the government of India is also following the same direction. ${ }^{14}$ This apart, COVID-19 patients also need to be educated on lifestyle, diet, and self-care approaches for managing symptoms during home isolation, involving naturopathy methods such as steam inhalation, nasal irrigation with saline water, cold sponging for fever, hot chest pack, arm and foot bath for chest congestion, along with home remedies for mild symptoms. It is imperative that we adopt an integrated, evidence-based approach of all health care systems to manage this pandemic effectively.

Table 1 Yoga practices in the management of COVID-19 patients

\begin{tabular}{|l|l|l|l|}
\hline $\begin{array}{l}\text { Yoga practices } \\
\text { (some important ones) }\end{array}$ & $\begin{array}{l}\text { Mild } \\
\text { disease }\end{array}$ & Moderate disease $^{\text {b }}$ & Physiological benefits $^{\text {a }}$ \\
\hline $\begin{array}{l}\text { Shvasa kriya (hand in and out and hands stretch breath- } \\
\text { ing)-9 rounds each }\end{array}$ & $\checkmark$ & $\checkmark$ & $\begin{array}{l}\text { Improve lung capacity and } \\
\text { respiratory effort }\end{array}$ \\
\hline Yogic breathing-9 rounds & $\checkmark$ & $\begin{array}{l}\text { Improve lung capacity and } \\
\text { respiratory effort }\end{array}$ \\
\hline Kapalabhati kriya (40-80 strokes/min)-3 roundsc & $\checkmark$ & $\begin{array}{l}\text { Facilitate mucociliary clear- } \\
\text { ance and secretions }\end{array}$ \\
\hline $\begin{array}{l}\text { Pranayam } \\
\text { nadishodana (1:1/1:2)-9 rounds } \\
\text { Bhramariv panayam-9 rounds }\end{array}$ & $\checkmark$ & $\begin{array}{l}\text { Facilitate relaxation response, } \\
\text { improve respiratory effort and } \\
\text { anti-inflammatory activity }\end{array}$ \\
\hline $\begin{array}{l}\text { Yogic relaxation/meditation technique with breath } \\
\text { awareness-5 minutes }\end{array}$ & $\checkmark$ & $\begin{array}{l}\text { Facilitate relaxation response } \\
\text { and reduce anxiety }\end{array}$ \\
\hline $\begin{array}{l}\text { Asanas-bhujangasana, ushtrasana, shashankasana, } \\
\text { sulabha matsyasa } \\
\text { Common yoga protocol if fit and asymptomatic (10-40 } \\
\text { min/day) }\end{array}$ & $\checkmark$ & $\begin{array}{l}\text { Awake proning/ } \\
\text { shashankasana/makarasana } \\
\text { breathing }\end{array}$ & $\begin{array}{l}\text { Improve respiratory effort and } \\
\text { lung capacity }\end{array}$ \\
\hline
\end{tabular}

a Mild disease-upper respiratory tract symptoms (and/or fever) without shortness of breath or hypoxia.

${ }^{b}$ Moderate disease-anyone of: 1 . respiratory rate $>24 /$ min, breathlessness 2 . SpO2: $90 \%$ to $<93 \%$ on room air. For severe disease, only awake proning/ shashankasana/makarasana breathing is advised for improving oxygen saturation and lung function.

cNot to be done while on oxygen supplementation and in those with dyspnoea or cough.

dIt is to be done in awake nonintubated patients only under supervision and $\mathrm{O} 2$ monitoring. Severe disease means: anyone of: 1 . respiratory rate $>30 /$ min, breathlessness 2 . SpO2 $<90 \%$ on room air. 


\section{Conflict of Interest}

None declared.

\section{References}

1 Thakur V, Jain A. COVID 2019-suicides: a global psychological pandemic. Brain, Behavior, and Immunity 2020;88:952-953

2 Deng J, Zhou F, Hou W, et al. The prevalence of depression, anxiety, and sleep disturbances in COVID-19 patients: a meta-analysis. Ann N Y Acad Sci 2021;1486(1):90-111

3 DeLongis A, Folkman S, Lazarus RS. The impact of daily stress on health and mood: psychological and social resources as mediators. J Pers Soc Psychol 1988;54(3):486-495

4 Duan L,Zhu G. Psychological interventions for people affected by the COVID-19 epidemic. Lancet Psychiatry 2020;7(4):300-302

5 Cohen S, Tyrrell DA, Smith AP. Psychological stress and susceptibility to the common cold. N Engl J Med 1991;325(9):606-612

6 Doyle WJ, Gentile DA, Cohen S. Emotional style, nasal cytokines, and illness expression after experimental rhinovirus exposure. Brain Behav Immun 2006;20(2):175-181

7 Chubak J, McTiernan A, Sorensen B, et al. Moderate-intensity exercise reduces the incidence of colds among postmenopausal women. Am J Med 2006;119(11):937-942

8 Nieman DC, Henson DA, Austin MD, Sha W. Upper respiratory tract infection is reduced in physically fit and active adults. $\mathrm{Br}$ J Sports Med 2011;45(12):987-992
9 Gleeson M, Bishop N, Lindley MR, Mastana S. The anti-inflammatory effects of exercise: Mechanisms and implications for the prevention and treatment of disease the role of muscle mass and body temperature in the inflammatory response to upper-body exercise and heat View project Concurrent exercise View project. Artic Nat Rev Immunol. 2011;11(9):607-615

10 Klentrou P, Cieslak T, MacNeil M, Vintinner A, Plyley M. Effect of moderate exercise on salivary immunoglobulin A and infection risk in humans. Eur J Appl Physiol 2002;87(2):153-158

11 Sallis R, Young DR, Tartof SY, et al. Physical inactivity is associated with a higher risk for severe COVID-19 outcomes: a study in 48440 adult patients. Br J Sports Med 2021. Doi:10.1136/bjsports-2021-104080

12 Barrett B, Hayney MS, Muller D, et al. Meditation or exercise for preventing acute respiratory infection: a randomized controlled trial. Ann Fam Med 2012;10(4):337-346

13 Vempati R, Bijlani RL, Deepak KK. The efficacy of a comprehensive lifestyle modification programme based on yoga in the management of bronchial asthma: a randomized controlled trial. BMC Pulm Med 2009;9:37

14 Fit India. 2020. Age appropriate fitness protocols. Available at: https://yas.nic.in/sites/default/files/Fitness\%20Protocols\%20 for\%20Age\%2018- 65\%20Years\%20v1\%20(English).pdf. Accessed June 2, 2021 